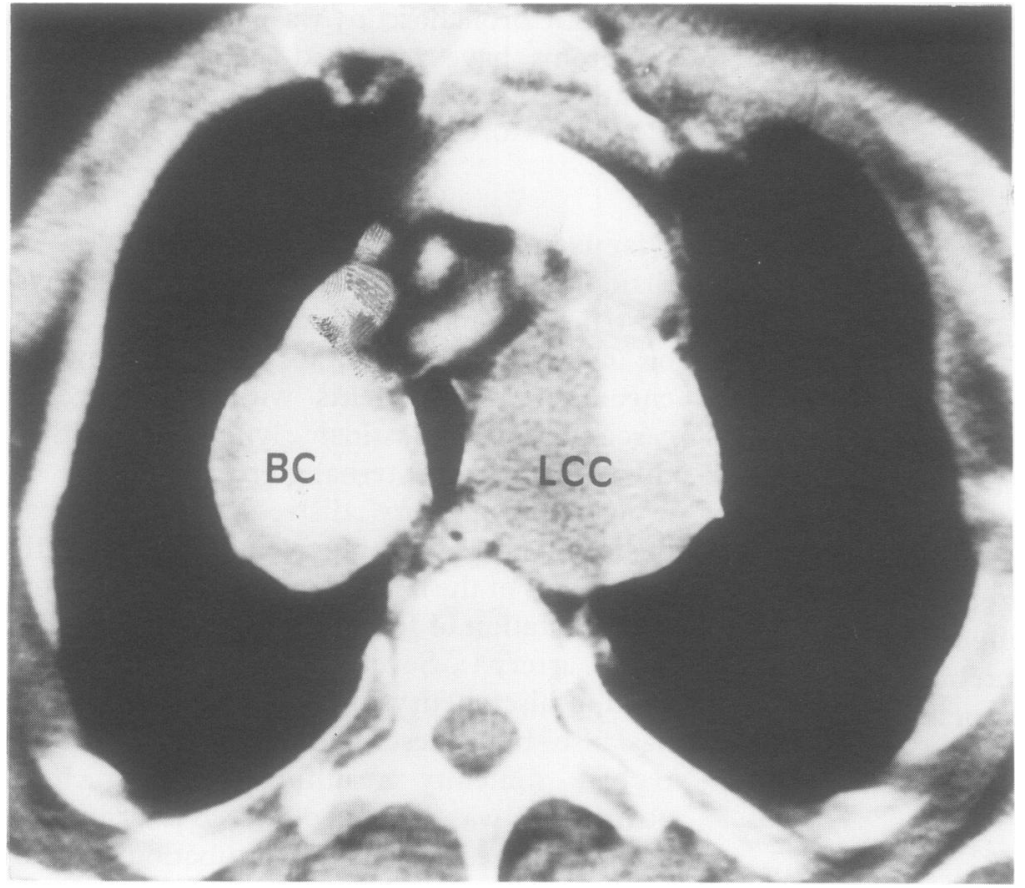

Figure 2 Computed tomographic scan section showing concurrent aneurysmal dilation of the brachiocephalic (BC) and left common carotid (LCC) arteries producing tracheal compression. their use in airways compression due to vascular aneurysms. A potentially fatal complication of stenting in this situation might be pressure necrosis leading to a bronchoarterial fistula. Medical management aimed at optimal control of blood pressure would seem the most appropriate course wherever possible.

We thank Miss Sharon Ritchie for secretarial assistance.

1 Murakami S, Urayama H, Kanehira E, Misaki T, Funaki Y, Iwa T. Successful emergency operation for tracheal obstruction caused by aneurysm of the aortic arch. NipponKyobu-Geka-Gakkai-Zasshi 1987;35:533-7.

2 Tominaga R, Tanaka J, Kawachi Y, Yoshitoshi M, Kohno $\mathrm{H}$, Shiki K, et al. Surgical management of respiratory insufficiency due to tracheobronchial compression by aneurysms of the ascending aorta and innominate artery. $f$ aneurysms of the ascending aorta

3 Nishiwaki K, Komatsu T, Shimada Y, Takeuchi E, Abe T. Severe tracheal compression caused by false aneurysm arising from the ascending aorta: successful airway management using induced hypotension and bronchoscopy. Anesthesiology 1990;73:1047-9.

4 Okutomi T, Shiraishi Y, Kato S, Ikeda K. A patient with bronchostenosis due to thoracic aortic aneurysm manifested by anaesthesia. Masui 1987;36:417-21.

5 Lindsay DC, Smith MCF, McQuillan PJ, Jordan MB. Laryngeal compression and stridor as the presenting feature of ruptured thoracic aortic aneurysm. $f$ Cardiovasc Surg 1989;30:864-6.

6 Simonds AK, Irving JD, Clarke SW, Dick R. Use of expandable metal stents in the treatment of bronchial obstruction. Thorax 1989;44:680-1.

7 George PJM, Irving JD, Mantell BS, Rudd RM. Covered expandable metal stent for recurrent tracheal obstruction. Lancet 1990;335:582-4.

\section{Childhood tuberculosis in Leeds, 1982-90: social and ethnic factors and the role of the contact clinic in diagnosis}

\author{
J M Goldman, C Teale, D B Cundall, \\ S B Pearson
}

The Leeds Chest

Clinic

J M Goldman

$S$ B Pearson

St James's University Hospital

C Teale

The General Infirmary at Leeds D B Cundall

Reprint requests to: Dr S B Pearson, The Leeds Chest Clinic, 74 New Briggate, Leeds LS1 6PH, Briggate

Received 28 October 1992 Returned to authors 9 February 1993 Revised version received 12 March 1993 Accepted for publication 6 May 1993

\begin{abstract}
A retrospective analysis of childhood tuberculosis in Leeds over a nine year period (1982-90) was performed which showed that the contact clinic is important for the early detection and treatment of disease in children. Two thirds of the cases of tuberculosis in children under 15 years were diagnosed and treated at the clinic. The incidence of tuberculosis was greater in Asian than in white children and, independent of race, was greater in the most deprived area of the city.
\end{abstract}

(Thorax 1994;49:184-185)

We have analysed the contribution of the screening services to the control of tuberculosis in children over the nine year period from the beginning of 1982 to the end of 1990 . The opportunity has also been taken to extend and strengthen our previous analysis of the ethnic and social factors influencing childhood tuberculosis. $^{1}$

\section{Methods}

In Leeds all tuberculosis notifications are forwarded to the chest clinic. In addition, copies of reports of positive microbiological and histopathological examinations are sent from laboratories within the city, allowing reminders about notification to be sent to clinical colleagues. Health visitors visit source cases, identify close contacts, and administer Heaf tests. All contacts then attend the chest clinic for reading of Heaf tests and chest radiographs if Heaf tests are positive.

In this survey all cases notified between January 1982 and December 1990 have been reviewed. Patients with atypical mycobacterial infections were not included in the analysis.

The population of Leeds is approximately 710000 including 19000 originating from the Indian subcontinent and 19000 belonging to other ethnic minority groups. ${ }^{2}$ The proportion of the population aged $0-14$ years was estimated as $34 \%$ people from the Indian subcontinent, $26 \%$ for other ethnic groups, and $18 \%$ for the white population..$^{23}$ The urban priority area of the city (population 200000 ) contains $60 \%$ of those claiming supplementary benefit, 
Number of cases of childhood tuberculosis, child population (aged 0-14 years), and mean annual rates by place of residence and ethnic origin in Leeds during the nine year period 1982-90

\begin{tabular}{lccc}
\hline Ethnic group & \multicolumn{2}{l}{ Place of residence } & \multirow{2}{*}{ Totals } \\
\cline { 2 - 3 } & UPA & Non-UPA & \\
\hline Indian subcontinent & $7 / 4900(15 \cdot 8)$ & $3 / 1600(20 \cdot 8)$ & $10 / 6500(17 \cdot 1)$ \\
Other non-white* & $11 / 4900(24 \cdot 9)$ & $6 / 1600(41 \cdot 7)$ & $17 / 6500(29 \cdot 1)$ \\
White & $3 / 3600(9 \cdot 3)$ & $0 / 1300$ & $3 / 4900(6 \cdot 8)$ \\
Totals & $0 / 3600$ & $0 / 1300$ & $0 / 4900$ \\
& $30 / 31500(10 \cdot 6)$ & $20 / 89600(2 \cdot 5)$ & $50 / 121100(4 \cdot 6)$ \\
& $37 / 31500(13 \cdot 0)$ & $15 / 89600(1 \cdot 9)$ & $52 / 121100(4 \cdot 8)$ \\
& $40 / 40000(11 \cdot 1)$ & $23 / 92500(2 \cdot 8)$ & $63 / 132500(5 \cdot 5)$ \\
& $48 / 40000(13 \cdot 3)$ & $21 / 92500(2 \cdot 5)$ & $69 / 132500(5 \cdot 8)$ \\
\hline
\end{tabular}

UPA $=$ urban priority area

* Two Afro-Caribbean, one Vietnamese.

Figures in parentheses are annual rate per 100000

Figures in the upper row refer to active cases, those in the lower row to children receiving chemoprophylaxis.

$60 \%$ of the unemployed, $75 \%$ of the ethnic minority population, $50 \%$ of the single parent families, and $40 \%$ of the elderly residing alone, but only $28 \%$ of the total city population.

\section{Results}

Sixty three children under 15 years were diagnosed as having active tuberculosis (table). Over all age groups the contact clinic in Leeds diagnosed $9 \%$ of the active tuberculosis, a figure which has not changed significantly in the last 20 years. ${ }^{4}$ For children under 15 years, however, 41 of 63 cases $(65 \%)$ with active disease were diagnosed by the contact tracing procedure. Nineteen of the remainder were diagnosed as hospital inpatients, and three who were not contacts were diagnosed in other clinics. All the cases diagnosed in the contact clinic had abnormal chest radiographs. Only five children out of the 63 with active disease had a history of BCG immunisation. In a further five children the BCG history was not known.

Sixty nine children in contact with tuberculosis received chemoprophylaxis for positive Heaf tests with normal chest radiographs (Heaf grade 3 or more, or grade 2 in the absence of a history of BCG immunisation). Two infants were given chemoprophylaxis because their mothers had sputum positive tuberculosis.

\section{ETHNIC AND SOCIAL FACTORS}

Children from families originating in the Indian subcontinent have an incidence of tuberculosis 3.7 (95\% confidence interval 1.9 to $7 \cdot 3$ ) times higher, and a chemoprophylaxis rate in contacts $6 \cdot 1(3.5$ to 10.5$)$ times higher, than white children. In agreement with our earlier findings, ${ }^{1}$ residence in the urban priority area is associated with an increased risk of tuberculosis with an incidence of tuberculosis $4.0(2.4$ to $6 \cdot 7)$ times higher, and a chemoprophylaxis rate in contacts $5.3(2.6$ to $7 \cdot 2)$ times higher, than in the more affluent parts of the city. For white children living in the urban priority area the incidence of tuberculosis is $4.3(2.4$ to $7 \cdot 5)$ times higher, and the chemoprophylaxis rate in contacts 7.0 (3.8 to 12.8$)$ times higher, than for white children living in the rest of the city. The probability of any of these results arising by chance is $<0.001\left(\chi^{2}\right.$ analysis with Yates' correction). Analysis of this larger number of cases strengthens our earlier conclusion that social deprivation is an important risk factor which is independent of ethnic background. The incidence of tuberculosis in deprived white children approaches that of the ethnic minority from the Indian subcontinent.

\section{Discussion}

The proportion of active cases of tuberculosis diagnosed by contact procedures is very similar in different centres, being $9 \%$ currently in Leeds and varying from $7 \cdot 5 \%$ to $12 \%$ in other published surveys. ${ }^{4-7}$ Although yields of screening (active cases as a proportion of those screened) are small - $0.63 \%$ currently in Leeds, $1.25 \%$ in our earlier study, ${ }^{4} 0.8 \%$ in Edinburgh, ${ }^{8}$ and $1.8 \%$ in Harrow $^{7}$ - two thirds of the cases of active childhood tuberculosis are detected in this way with a similar number of children identified as requiring chemoprophylaxis.

Our initial finding ${ }^{1}$ that tuberculosis in Leeds is equally common in white and Asian children is now shown not to be true. However, the incidence in the two groups is similar in the socially deprived urban priority area. Our earlier finding ${ }^{1}$ that social deprivation and poverty are important factors for tuberculosis in children is strengthened by our current study, and again it emerges that at least $84 \%$ of the children with tuberculosis had not had BCG immunisation. More effective control might be achieved by extending neonatal immunisation from Asian children, as currently practised, to include other vulnerable groups within the white population. However, a more detailed index of child deprivation based on smaller area statistics than the urban priority area would be desirable.

1 Cundall DB, Pearson SB. Inner city tuberculosis and immunisation policy. Arch Dis Child 1988;63:964-85.

2 Leeds City Council Planning Department. Report on ethnic minority populations. Leeds: Leeds City Council, 1986.

3 Nunn J, Darbyshire JH, Fox W, Johnson DA, Springett VH. Changes in annual tuberculosis notification rates between 1977-78 and 1983 for the population of Indian subcontinent ethnic origin resident in England. $\mathcal{F}$ Epidemiol Comnent ethnic origin resident in Eng
munity Health 1986;40:357-63.

4 Byram D, Hatton P, Williams S, Pearson SB. The form and presentation of tuberculosis over a 10-year interval in Leeds. Br $\mathcal{F}$ Dis Chest 1985;79:152-60.

5 Capewell S, Leitch AG. The value of contact procedures for tuberculosis in Edinburgh $B r \mp$ Dis Chest 1984;78:317-29.

6 Allen MB, Selby CD, Leitch AG. Changing patterns of tuberculosis in Edinburgh. Thorax 1990;45:821.

7 Thomas PS, Harries MG. The value of a tuberculosis contact clinic in Harrow. Thorax 1988;43:834.

8 Selby CD, Allen MB, Leitch AG. Optimal duration of radiological follow-up for tuberculosis contacts. Respir Med 1989;83:353-5. 